\title{
Video Article \\ Full-field Strain Measurements for Microstructurally Small Fatigue Crack Propagation Using Digital Image Correlation Method
}

\author{
Evgenii Malitckii ${ }^{1}$, Heikki Remes ${ }^{1}$, Pauli Lehto ${ }^{1}$, Sven Bossuyt ${ }^{1}$ \\ ${ }^{1}$ Department of Mechanical Engineering, Aalto University School of Engineering
}

Correspondence to: Evgenii Malitckii at evgeny.malitskiy@aalto.fi

URL: https://www.jove.com/video/59134

DOI: doi:10.3791/59134

Keywords: Engineering, Issue 143, Digital image correlation, small fatigue crack, crack growth rate retardation, sub grain level, shear strain localization, strain inhomogeneity.

Date Published: 1/16/2019

Citation: Malitckii, E., Remes, H., Lehto, P., Bossuyt, S. Full-field Strain Measurements for Microstructurally Small Fatigue Crack Propagation Using Digital Image Correlation Method. J. Vis. Exp. (143), e59134, doi:10.3791/59134 (2019).

\section{Abstract}

A novel measurement approach is used to reveal the cumulative deformation field at a sub-grain level and to study the influence of microstructure on the growth of microstructurally small fatigue cracks. The proposed strain field analysis methodology is based on the use of a unique pattering technique with a characteristic speckle size of approximately $10 \mu \mathrm{m}$. The developed methodology is applied to study the small fatigue crack behavior in body centered cubic (bcc) Fe-Cr ferritic stainless steel with a relatively large grain size allowing a high spatial measurement accuracy at the sub-grain level. This methodology allows the measurement of small fatigue crack growth retardation events and associated intermittent shear strain localization zones ahead of the crack tip. In addition, this can be correlated with the grain orientation and size. Thus, the developed methodology can provide a deeper fundamental understanding of the small fatigue crack growth behavior, required for the development of robust theoretical models for the small fatigue crack propagation in polycrystalline materials.

\section{Video Link}

The video component of this article can be found at https://www.jove.com/video/59134/

\section{Introduction}

New lightweight solutions are required to improve the energy efficiency of vehicles such as ships. Weight reduction of large steel structures is possible using advanced steel materials. The efficient utilization of new material and the lightweight solution requires high manufacturing quality and robust design methods ${ }^{1,2}$. A robust design method means structural analysis under realistic loading conditions, such as wave-induced loading in the case of a cruise ship, as well as response calculations to define deformation and stresses. The allowed stress level is defined based on the strength of critical structural details. In the case of large structures, these are typically welded joints with an inhomogeneous microstructure. One of the key design challenges for new lightweight solutions is fatigue due to its cumulative and localized nature, often taking place at weld notches. For high manufacturing quality, the fatigue behavior is dominated by small fatigue crack (SFC) growth since manufacturing induced defects are very small ${ }^{1,3}$. Thus, the fundamental understanding of small fatigue crack growth in metallic materials is crucial for sustainable use of new steels in high performance structures.

The effective modeling of such a complicated process as fatigue crack propagation in polycrystalline metallic materials is impossible without a clear understanding of the physical processes accompanying the fatigue fracture mechanism. A significant effort from the research community has been focused on investigating fatigue crack propagation using visual observation and statistical analysis. So far, small fatigue crack growth behavior has mainly been investigated by theoretical methods due to the limitations of experimental techniques. The anomalous fatigue crack growth rate retardation for SFCs is usually associated with the grain boundaries $(\mathrm{GB})^{4,5,6,7,8,9}$. However, the reasons for anomalous SFC growth are still under discussion. The results obtained by theoretical modelling using a discrete dislocation method shows formation of a dislocation wall, or a short low-angle grain boundary caused by dislocations emitted from the fatigue crack tip affecting the fatigue crack growth rate ${ }^{10,11,12,13}$. Until recently, there has been a challenge in accurate experimental analysis of the small fatigue crack growth behavior. Experimental observations are required for the development of physical principles based computational models.

For analysis of cyclic material deformation behavior at micro-scale it is desirable to have full-field deformation measurements that can be carried out in situ during cyclic loading using standard mechanical testing equipment, with spatial resolution at least an order of magnitude below the characteristic length scale of the microstructure. In order to understand the variations in fatigue crack growth rate, measured strain fields are often linked to electron backscatter diffraction (EBSD) measurements of material microstructure. Carrol et al. ${ }^{14}$ provide a quantitative, full-field ex situ measurement of plastic strain near a growing long fatigue crack in a nickel-based super alloy, showing the formation of asymmetric lobes in the plastic wake of the propagating fatigue crack. At higher magnification, electron microscopy digital image correlation (DIC) revealed strain inhomogeneities associated with strain localization on the slip bands, with twin and grain boundaries affecting the fatigue crack growth behavior. However, the used ex situ measurement approach is not able to capture the strain field during fatigue crack propagation. An experimental study of plastic blunting during long fatigue crack propagation was performed by Peralta ${ }^{15}$ using in situ DIC for commercial purity Ni (99.6\%). Results revealed that the accumulation of plastic deformation was dominated by shear along the slip bands that extended ahead of the crack 
and were inclined with respect to the crack growth direction. The observed strain localization at the slip bands is probably caused by overloading, since the low stress intensity factor values result in a mixed nature of the deformation (shear and normal strain) ${ }^{14,15}$. A heterogeneous strain field distribution at the sub-grain level has been observed for coarse grained aluminum alloy ${ }^{16}$ and duplex steel ${ }^{17}$, where the activation of the dislocation slip systems was associated with Schmid`s law ${ }^{16,17}$.

A recent study performed by Malitckii ${ }^{18}$ manifests that anomalous SFC growth behavior is controlled by strain inhomogeneities related to the grain structure or, in particular, by accumulation of shear strain localization zones ahead of the crack. With high-quality micro-scale patterns and grains larger than $100 \mu \mathrm{m}$, optical microscopy DIC enabled in situ sub-grain deformation measurements for the first time. However, in Malitckii ${ }^{18}$, the novel methodology applied to measure plastic strain field in situ over hundreds of thousands of load cycles was not presented or discussed in detail. Therefore, the objective of this paper is to introduce this new experimental approach for studying small fatigue crack growth behavior in polycrystalline materials in the high cycle regime. The novelty of the approach consists of in situ full-field strain measurement using a unique pattern technique, in addition to crack growth rate measurement. Because this method uses optical image sensors it enables capturing thousands of frames during the fatigue test. Electron backscatter diffraction (EBSD) is used for microstructural characterization and combined with DIC measurements to reveal the impact of grain boundaries on small fatigue crack growth retardation ${ }^{18}$. The approach is applied for the measurement of small fatigue crack propagation in bcc $18 \% \mathrm{Cr}$ ferritic stainless steel ${ }^{18}$ simulating the behavior of the structural steel for large structural applications. In this paper, we explain the main steps of the measurement procedure and provide a summary discussion of the main finding.

\section{Specimen preparation and annealing}

1. Mill the original ferritic stainless-steel plates with a thickness of $3 \mathrm{~mm}$ (see Table of Materials) to form the plate with characteristic size of about $200 \mathrm{~mm} \times 15 \mathrm{~mm} \times 1 \mathrm{~mm}$.

2. Place the produced steel plate into the quartz tube and pump (see Table of Materials) it until the pressure of about $10^{-6} \mathrm{mbar}$.

3. Provide argon gas (see Table of Materials) into the quartz tube until the pressure reaches about $0.2 \mathrm{mbar}$.

4. Seal the quartz tube with the specimen inside by heating the quartz tube up to the melting temperature ${ }^{19}$.

CAUTION: The sealing procedure is hazardous. Use appropriate precautions such as proper eye protection, etc. ${ }^{20}$

5. Anneal the steel plate sealed inside of the quartz tube using the chamber furnace (see table of materials) at temperature of $1200{ }^{\circ} \mathrm{C}$ for $1 \mathrm{~h}$ and quench in water.

NOTE: The annealing procedure increases the average grain size of the studied steel up to $350 \mu \mathrm{m}$ without extensive formation of chromium carbide particles ${ }^{21}$.

CAUTION: The annealing procedure is hazardous. Use appropriate precautions and follow the instructions of the chamber furnace manual.

6. Cut notched specimens (with thickness of $1 \mathrm{~mm}$ ) from the annealed plate of the studied ferritic steel using electrical discharge machining (EDM, see Table of Materials). The scheme of the specimen is shown in Figure 1.

CAUTION: The EDM cutting procedure is hazardous. Use appropriate precautions and follow the instructions of the EDM manual.

7. Grind and polish the specimen surface.

1. Grind the specimen surfaces using grinding machine with emery paper (Table of Materials) until the surface of the specimen is uniform.

2. Polish the specimen surfaces using the polishing machine with $3 \mu \mathrm{m}$ and $1 \mu \mathrm{m}$ diamond paste (see Table of Materials) for $10 \mathrm{~min}$ each.

3. Polish the specimen surface using $0.02 \mu \mathrm{m}$ colloidal silica vibratory polishing (see table of materials) for about $4 \mathrm{~h}$; this is required for EBSD analysis.

\section{Fatigue pre-cracking}

1. Experimentally define the displacement controlled fatigue test parameters.

1. Adjust the displacement limits $\varepsilon_{\min }$ and $\varepsilon_{\max }$ of the servo hydraulic machine (see Table of Materials) so that the $\sigma_{\min }$ and $\sigma_{\max }$ are in range of about $-50 \mathrm{MPa}$ and $300 \mathrm{MPa}$, respectively.

CAUTION: The servo hydraulic machine is hazardous. Use appropriate precautions and follow the instructions of the servo hydraulic machine manual.

2. Examine the initial crack formation after 2,000, 5,000 and 10,000 cycles using optical microscopy (see Table of Materials) to define the optimal number of fatigue cycles and avoid extensive crack growth.

2. Subject the specimen to displacement controlled uniaxial cyclic loading for defined amount of cycles.

3. Examine the initial crack formation after defined amount of cycles using optical microscopy. Initial cracks with lengths up to about $20 \mu \mathrm{m}$ are produced at the notch tip.

4. Increase the number of the fatigue loading cycles if the initial crack was not produced

5. Replace the specimen if the initial crack length exceeds $50 \mu \mathrm{m}$.

\section{Microstructural characterization}

1. Clean the pre-cracked specimen

1. Clean the pre-cracked specimen with acetone for 20 min using the ultrasonic bath (see Table of Materials).

2. Clean the pre-cracked specimen with ethanol for $20 \mathrm{~min}$ using the ultrasonic bath (see Table of Materials).

2. Mark the studied area using Vickers microindentations as shown in Figure 2a. 
1. Follow the instructions of the Vickers microindentor (see Table of Materials) to perform the microindentation marks.

2. Insert the specimen into the micro Vickers hardness tester (see Table of Materials).

3. Set the indentation force at $500 \mathrm{~N}$.

4. Adjust the position for the first Vickers indentation mark at about $500 \mu \mathrm{m}$ sideways from the notch tip. Prepare the second indentation at another side.

5. Adjust the position for the third indentation mark at about $500 \mu \mathrm{m}$ sideways and about $400 \mu \mathrm{m}$ away from the notch tip.

3. Analyze the microstructure of the steel from the side surface of the specimen in the vicinity of the notch using electron backscatter diffraction (EBSD) analysis (see Table of Materials).

1. Follow the instruction manual of scanning electron microscope to perform EBSD analysis.

2. Set the magnification at $200 x$.

3. Adjust the position of the specimen under EBSD detector. Ensure that the notch tip and three Vickers microindentation marks are within the framework of the EBSD scanning (see Figure 2b).

4. Set the step size of the EBSD scanning at $2 \mu \mathrm{m}$. Scanning duration is about $1 \mathrm{~h}$.

\section{Decoration with a pattern}

1. Clean the specimen surface with ethanol (see Table of Materials) for 10 min using the ultrasonic bath.

2. Dry the specimen using a fan.

3. Clean a microscope slide using a paper napkin soaked with ethanol (see Table of Materials).

4. Deposit a thin layer of ink on the glass surface of the microscope slide. A permanent marker provides uniform layer of ink on the glass surface by hand.

5. Press down on the silicone stamp with the pattern on the glass surface to transfer a layer of ink to the stamp surface.

6. Press down on the silicone stamp covered with the ink on the specimen surface.

7. Check the speckle pattern quality using optical microscopy. An example of the speckle pattern is shown in Figure 3 . See references ${ }^{22,23}$ for details of pattern and microcontact printing.

8. Ensure that the speckle pattern size is at least 10 times smaller than the grain size of the studied material. NOTE: Perform the steps 2, 3 and 4 in sufficient time to avoid the ink drying. Define the drying time experimentally.

\section{Fatigue testing with DIC}

1. Set the specimen into the servo hydraulic machine (see table of materials). CAUTION: The servo hydraulic machine is hazardous. Use appropriate precautions and follow the instructions of the servo hydraulic machine manual.

2. Adjust the load-controlled fatigue test parameters using $\mathrm{R}=0.1\left(\sigma_{\min }=35 \mathrm{MPa}, \sigma_{\max }=350 \mathrm{MPa}\right)$ and test frequency of $10 \mathrm{~Hz}$ using the control software of the fatigue machine.

3. Set up an optical microscope with 16x precision zoom lens (see Table of Materials) for optical observation of the specimen notched area.

4. Equip the optical microscope with a digital camera with resolution of 2,048 pixels $\times 1,536$ pixels.

5. Adjust the magnification of the optical microscope manually.

1. Ensure that the whole notched area of the specimen fits into the image area of the digital camera.

2. Ensure that the pixel size is at least 5 times smaller than the pattern size.

6. Run the fatigue test and synchronize with the image recording system.

1. Capture the images during temporary ( $10 \mathrm{~s}$ ) stops of the fatigue test in intervals of 500 cycles.

2. Ensure that the load is held constant with an average stress of about $210 \mathrm{MPa}$ during image acquisition.

7. Continue the fatigue testing until the crack length approaches a critical value or net-section plasticity starts to dominate.

\section{Results analysis}

1. Use the obtained raw images to perform the crack growth rate (CGR) and DIC analysis using a commercial software (see Table of Materials).

1. Use the operation manual to perform CGR analysis. Note that the crack growth rate analysis is possible to perform using the commercial software automatically or manually.

2. Perform the CGR analysis manually using the raw image dataset by measurement of the crack length increment after each 500 cycles.

2. Analyze of the shear strain deformation for the studied area using commercial software.

1. Use the operation manual to perform shear strain deformation analysis.

2. Ensure that correlation mode in time series settings of the software is chosen to be "relative to the first".

3. Perform Schmid factor and grains misorientation analysis of EBSD data using the open source MTEX toolbox (see Table of Materials). NOTE: Details about Schmid factor and grains misorientation analysis are available in user guide of MTEX toolbox ${ }^{24}$.

4. Perform cumulative analysis of the obtained results.

NOTE: The cumulative analysis is discussed in Ref. ${ }^{18}$.

1. Use Vickers microindentation marks to match the grain boundary map, misorientation map and Schmid factor map on top of the shear strain deformation field ${ }^{18}$. 
2. Define the correlation between CGR, strain field and microstructure (misorientation and Schmid factor maps) ${ }^{18}$.

\section{Representative Results}

Using the proposed methodology, we can analyze the sub-grain deformation field accumulating during small fatigue crack propagation under cyclic loading. The characterization is performed at sub grain level showing tiny features of the material behavior under fatigue loading even within a single grain. In particular, formation of shear strain localization fields was observed as shown in Figure 4. A number of tests were performed to verify the observed phenomena.

The deformation field is easily combined with the grain boundary image for a comprehensive characterization of the features responsible for the anomalous growth behavior of the small fatigue cracks (see Figure 5). Cumulative analysis of the deformation field, microstructure, crack growth rate and crack path reveal a dependence between the small crack growth rate retardation and accumulation of the shear strain localization zone $^{18}$, as shown in the video.

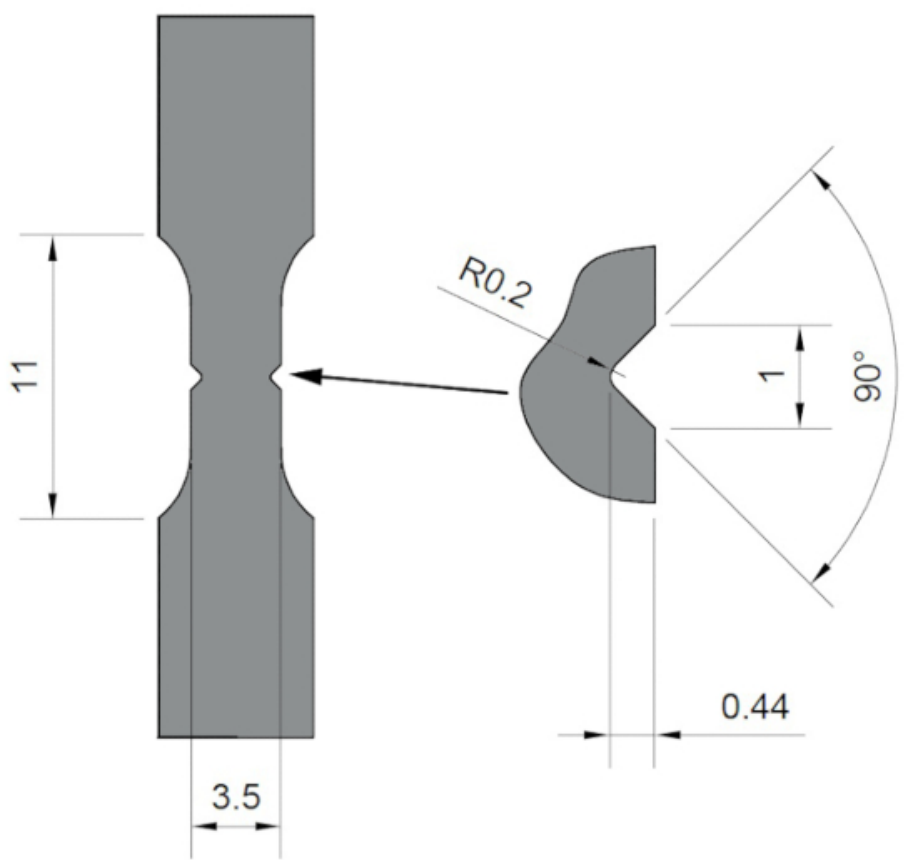

Figure 1: Schematic view of the fatigue test specimen of the studied ferritic stainless steel (dimensions are in $\mathrm{mm}$ ). Please click here to view a larger version of this figure. 

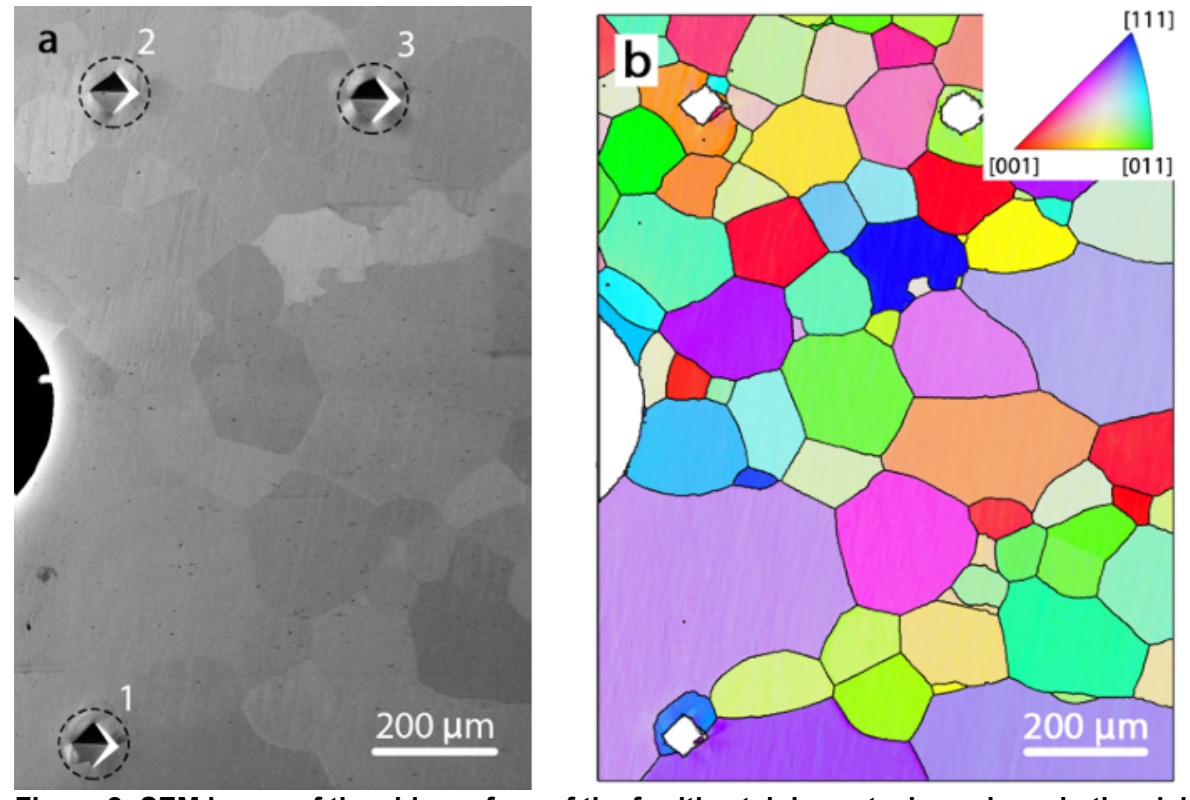

Figure 2: SEM image of the side surface of the ferritic stainless steel specimen in the vicinity of the notched area (a) and its inverse pole figure (IPF) map with IPF key in the inset (b). The alignment of the DIC strain field and EBSD image was performed with help of Vickers microindentations shown by dashed circles (a). Please click here to view a larger version of this figure.

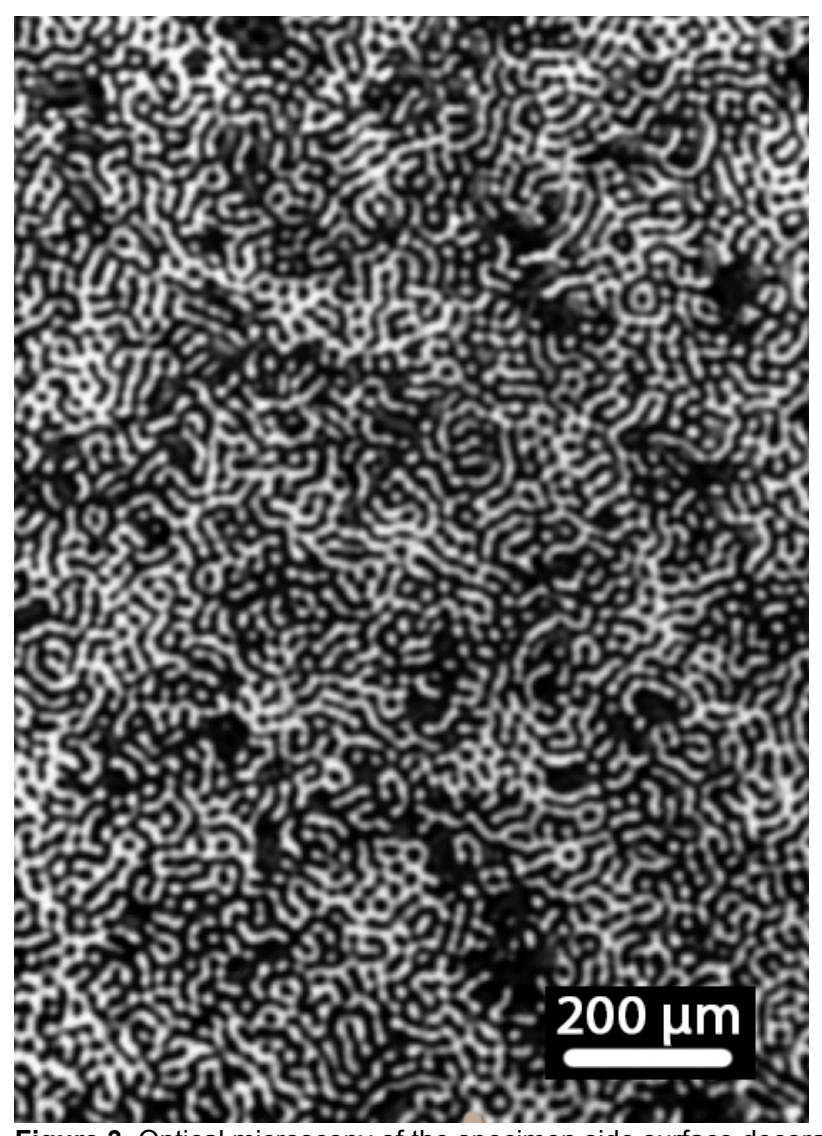

Figure 3. Optical microscopy of the specimen side surface decorated with a pattern. 

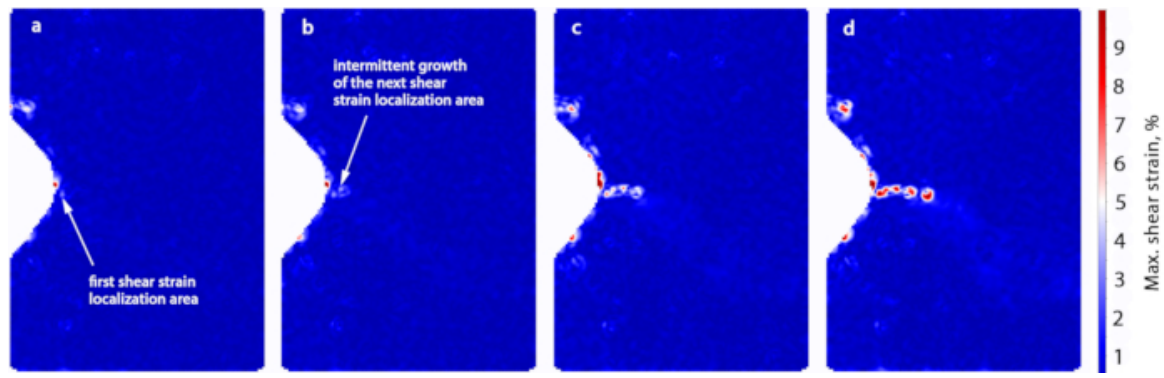

Figure 4. Intermittent accumulation of the shear strain localization zones during small fatigue crack growth. Please click here to view a larger version of this figure.
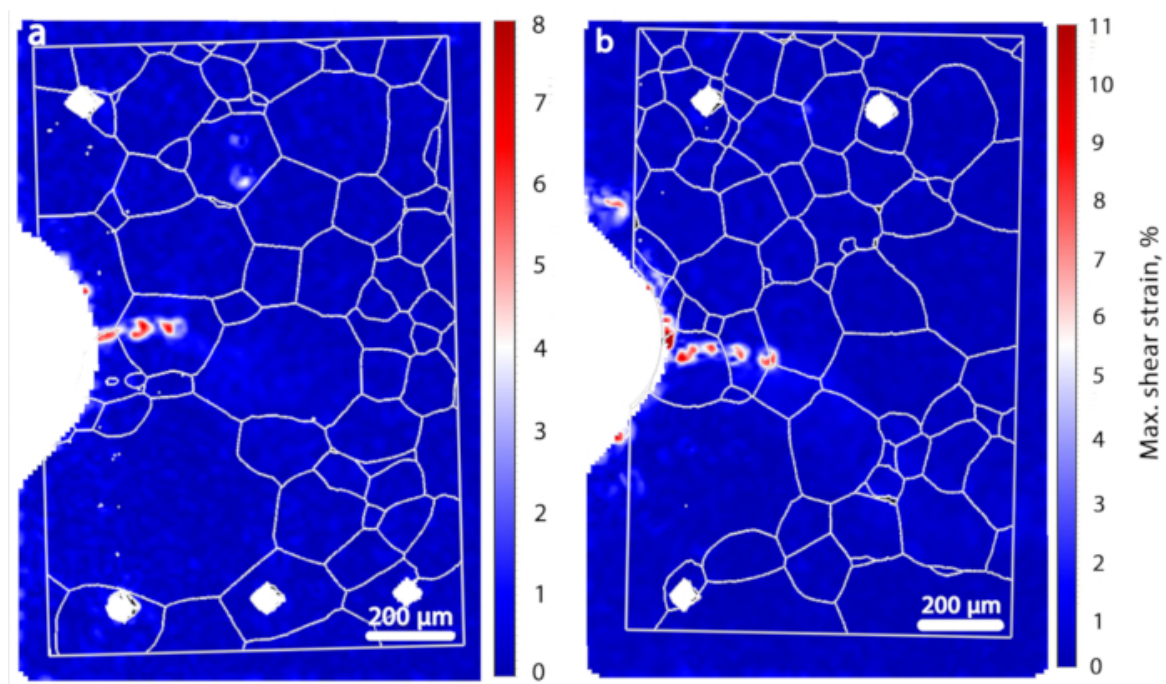

Figure 5. Two examples ( $a$ and $b$ ) of the combined view of the shear strain field and microstructure of the studied steel tested in fatigue. Please click here to view a larger version of this figure. 


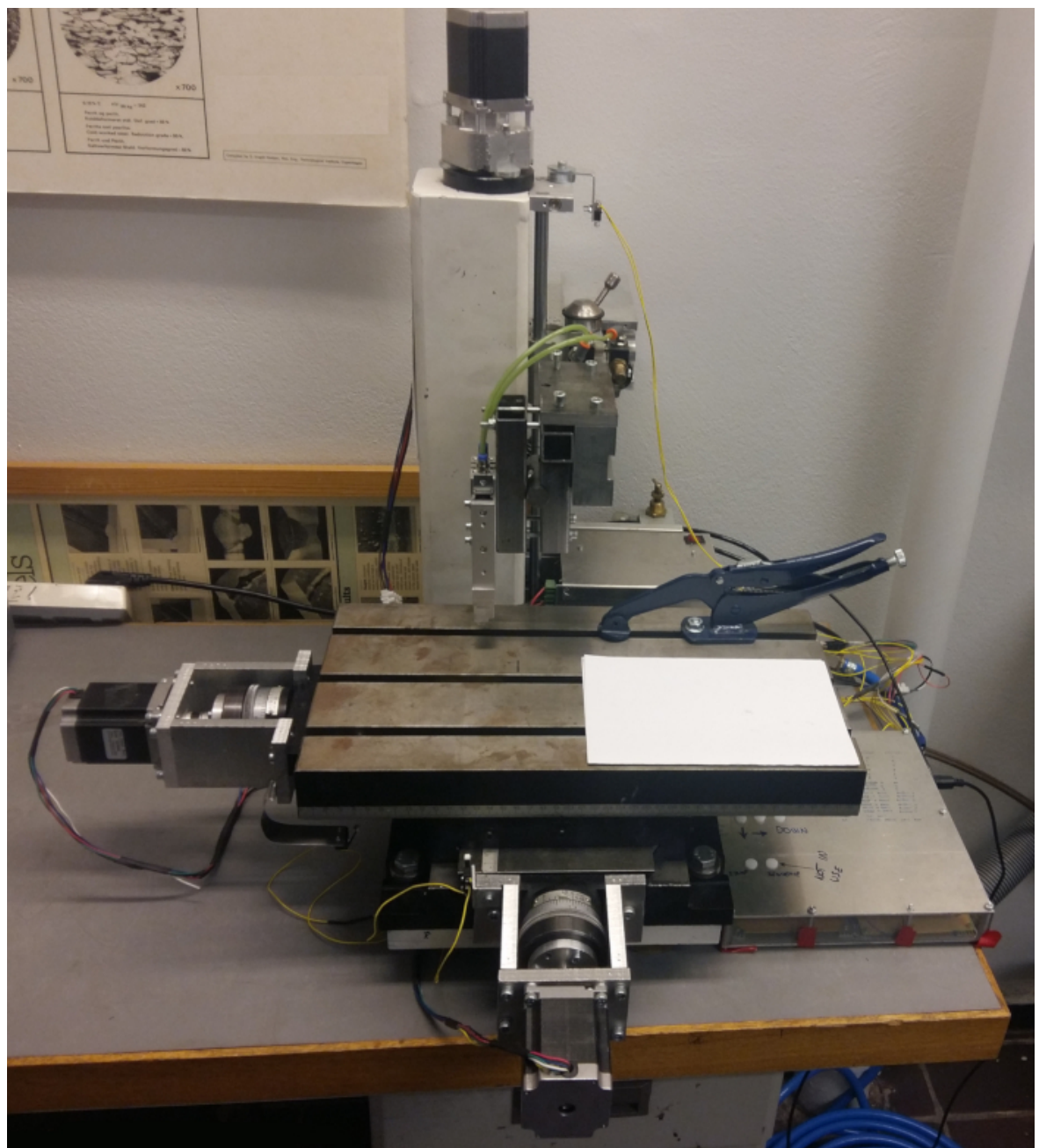

Figure 6. Custom-made pneumatic machine for pattern decoration of the specimens. Please click here to view a larger version of this figure.

\section{Discussion}

A novel in situ measurement approach is introduced to measure the cumulative deformation field at a grain micro-scale level. In order to demonstrate the approach capability, the microstructurally small fatigue crack propagation behavior is studied in ferritic stainless steel with $18 \%$ chromium. The studied steel was provided in the shape of hot rolled plate with a thickness of $3 \mathrm{~mm}$ (see Table of Materials) and average grain size of about $17 \mu \mathrm{m}^{21}$.

A successful measurement requires that an initial fatigue crack is produced at the notch tip of the specimens for further propagation behavior analysis. In order to study a microstructurally small crack, the length of the initial crack should be significantly smaller than the grain size of the studied steel. Fatigue testing is displacement controlled to prevent crack growth after fatigue crack initiation. It was found that fatigue crack initiation time decreases significantly with the decrease of stress ratio $(R)$. Thus, only 10,000 cycles were required for fatigue crack initiation in the specimens tested with R-ratio -0.16 , while with Rratio 0.1 , the fatigue crack did not initiate even after 100,000 cycles. The use of the load ratio $R=-0.16$ allows to increase the stress range from $315 \mathrm{MPa}$ to $350 \mathrm{MPa}$, having still smaller maximum stress for pre-cracking than that of actual fatigue testing.

The intermittent small fatigue crack growth is usually associated with the microstructure. In particular, grain boundaries are widely considered as microstructural features responsible for small crack growth retardation ${ }^{4,5,6,7,8,9,10,11,12}$. The dislocation formulation in the boundary element by Hansson et al. ${ }^{13}$ shows that the low-angle grain boundaries lying in the way of the crack path can result in both an increase and decrease of the crack growth rate; however, the high-angle grain boundaries do not affect the crack growth rate. The physical reasons causing the anomalous crack growth behavior are not well known. In order to reveal the microstructural features causing the small crack retardation, a microstructural characterization was performed before fatigue testing of the specimen. The polishing procedure described in step 1 is crucial for reliable microstructural analysis using EBSD. In step 3, just before EBSD analysis, the cleaning of the specimen in ethanol is only allowed, since acetone vapor is hazardous for EBSD detector.

In order to reveal deformation processes within individual grains, the size of the speckle pattern must be significantly smaller than the grain size of the studied steel. Since the average grain size of the steel after annealing is about $350 \mu \mathrm{m}$, the characteristic size of the speckle pattern required for DIC calculation was chosen to be approximately $10 \mu \mathrm{m}^{22,12}$. The speckle pattern size must be at least 10 times smaller than the 
grain size of the studied steel for proper implementation of step 5. The surface of the specimen is decorated with a speckle pattern using a silicone stamp. We use a custom-made pneumatic tool (see Figure 6) for fast and precise operation of the stamp.

Small fatigue crack propagation behavior is studied during load-controlled fatigue testing of the pre-cracked specimens using the R-ratio of 0.1 $\left(\sigma_{\min }=35 \mathrm{MPa}, \sigma_{\max }=350 \mathrm{MPa}\right)$ and the frequency of $10 \mathrm{~Hz}$. Fatigue testing follows together with digital image correlation (DIC) measurement. The area of interest is monitored using an optical microscope, 16x Precision Zoom Lens, with a resolution of $2 \mu \mathrm{m} /$ pixel. Images are captured during temporary $(10 \mathrm{~s})$ stops of the fatigue test in intervals of 500 cycles. During image acquisition, the loading is held constant, with an average stress of approximately $210 \mathrm{MPa}$, in order to have equal loading conditions for all images, stabilize plastic deformation, and avoid fatigue crack closure and extensive creep accompanied with min and max of loading force, respectively. The novelty of the method is based on highresolution in situ DIC image recording that allows to reveal tiny deformation zones forming during small fatigue crack growth. The success of the experiment depends on the proper implementation of the pre-cracking procedure, selection of image capture interval and magnification to prevent the blurring of small features such as the observed shear strain localization zones. Thus, proper selection of camera resolution, optical magnification and speckle pattern size as described in step 5 of the protocol can be crucial for investigation of the strain localization phenomena. However, morphology of the shear strain localization zones is still unclear and needs further improvements of the speckle pattern and resolution of the image recording equipment.

The methodological approach described in this paper is suitable for crack growth analysis of small fatigue cracks in coarse-grained materials. A combination of crack growth rate measurement and strain-field analysis at the sub grain level helps to reveal the mechanism that are responsible for anomalous growth of the small fatigue cracks ${ }^{18}$, in addition to the widely observed grain boundary effects on SFCs. Deeper understanding of the fatigue fracture mechanisms makes development of new theoretical approaches possible and thus, enables design of lighter and more energy efficient structures in the future.

\section{Disclosures}

The authors have no competing financial interests to disclose.

\section{Acknowledgements}

The ASTM UNS S43940 ferritic stainless steel was provided by Outokumpu Stainless Oyj. Research is supported by Academy of Finland project № 298762 and Aalto University School of Engineering and by post-doctoral funding No 9155273 Aalto University School of Engineering. Video publication was performed with support of Mikko Raskinen from Aalto Media Factory.

\section{References}

1. Remes, H. et al. Factors affecting the fatigue strength of thin-plates in large structures. International Journal of Fatigue. 101, 397-407 (2017).

2. Lillemäe, I., Remes, H., Liinalampi, S., Itävuo, A. Influence of weld quality on the fatigue strength of thin normal and high strength steel butt joints. Welding in the World. 60, 731-740 (2016).

3. Remes, H. Strain-based approach to fatigue crack initiation and propagation in welded steel joints with arbitrary notch shape. International Journal of Fatigue. 52, 114-123 (2013).

4. Tokaji, K., Ogawa, T. The growth behavior of microstructurally small fatigue cracks in metals. Short Fatigue Cracks, ESIS 13 (Edited by K.J. Miller and E.R. de los Rios), Mechanical Engineering Publication, London., 85-89 (1992).

5. Tokaji, K., Ogawa, T., Harada, Y. Evaluation on limitation of linear elastic fracture mechanics for small fatigue crack growth. Fatigue \& Fracture of Engineering Materials \& Structures. 10, 281-289 (1987).

6. Tokaji, K., Ogawa, T. Short Fatigue Cracks, ESIS 13, in: K.J. Miller, E.R. de los Rios (Eds.), The growth behavior of microstructurally small fatigue cracks in metals, Mechanical Engineering Publications, London., 85-89 (1992).

7. McClintock, F.A. On the plasticity of the growth of fatigue cracks. Fracture of Solids. 20, 65-102 (1963).

8. Doquet, V. Micromechanical simulations of microstructure-sensitive stage I fatigue crack growth. Fatigue \& Fracture Engineering Materials \& Structures. 22, 215-223 (1998).

9. Ohr, S.M. An electron microscope study of crack tip deformation and its impact on the dislocation theory of fracture. Materials Science and Engineering. 72, 1-35 (1985).

10. Bjerkén, C., Melin, S. Influence of low-angle grain boundaries on short fatigue crack growth studied by a discrete dislocation method. In: Proceedings of the 17th European Conference Fractur.e, VUTIUM Brno, Czech Republic, 2-5 September (2008).

11. Bjerkén, C., Melin, S. Growth of a short fatigue crack - a long term simulation using a dislocation technique. International Journal of Solids and Structures. 46, 1196-1204 (2009).

12. Shen, Z., Wagoner, R.H., Clark, W.A.T. Dislocation and grain boundary interactions in metals. Acta Metallurgica. 36, 3231-3242 (1988)

13. Hansson, P., Melin, S. Grain boundary influence on short fatigue crack growth rate. International Journal of Fracture. 165, 199-210 (2010).

14. Carroll, J.D., Abuzaid, W., Lambros, J., Sehitoglu, H. High resolution digital image correlation measurements of strain accumulation in fatigue crack growth. International Journal of Fatigue. 57, 140-150 (2013).

15. Peralta, P., Choi, S.-H., Gee, J. Experimental quantification of the plastic blunting process for stage II fatigue crack growth in one-phase metallic materials. International Journal of Plasticity. 23, 1763-1795 (2007).

16. Zhang, N., Tong, W. An experimental study on grain deformation and interactions in an Al- $0.5 \% \mathrm{Mg}$ multicrystal. International Journal of Plasticity. 20, 523-542 (2004).

17. Bartali, A.E., Aubin, V., Degallaix, S. Surface observation and measurement techniques to study the fatigue damage micromechanisms in a duplex stainless steel. International Journal of Fatigue. 31, 2049-2055 (2009).

18. Malitckii, E., Remes, H., Lehto, P., Yagodzinskyy, Y., Bossuyt, S., Hänninen, H. Strain accumulation during microstructurally small fatigue crack propagation in bcc Fe-Cr ferritic stainless steel. Acta Materialia. 144, 51-59 (2018).

19. http://www.ilpi.com/glassblowing/tutorial_ampule.html. (2018). 
20. http://www.ilpi.com/msds/ref/ppe.html. (2018).

21. Malitckii, E., Yagodzinskyy, Y., Lehto, P., Remes, H., Romu, J., Hänninen, H. Hydrogen effects on mechanical properties of $18 \%$ Cr ferritic stainless steel. Material Science and Engineering A. 700, 331-337 (2017).

22. Bossuyt, S. Optimized patterns for digital image correlation. Proceedings of the 2012 Annual Conference on Experimental and Applied Mechanics, Imaging Methods for Novel Materials and Challenging Applications. 3, 239-248 (2013).

23. Coren, F., Palestini, C., Lehto, M., Bossuyt, S., Kiviluoma, P., Korhonen, A., Kuosmanen, P. Microcontact printing on metallic surfaces for optical deformation measurements. Proceedings of the Estonian Academy of Scienc.es. 66, 184-188 (2017).

24. Documentation. http://mtex-toolbox.github.io/documentation.html (2018). 